\title{
Editorial: The Impact of Place-Based Contextualised Curriculum on Student Engagement and Motivation in STEM Education
}

\author{
Kathryn Holmes ${ }^{1 *}$, Nathan Berger ${ }^{1}$, Erin Mackenzie ${ }^{1}$, Catherine Attard ${ }^{1}$, Patrick Johnson ${ }^{2}$, \\ Olivia Fitzmaurice ${ }^{2}$, Niamh O'Meara ${ }^{2}$ and Veronica Ryan ${ }^{2}$ \\ ${ }^{1}$ Centre for Educational Research, School of Education, Western Sydney University, Penrith, NSW, Australia, ${ }^{2}$ School of \\ Education, University of Limerick, Limerick, Ireland
}

Keywords: stem education, place-based learning, contextualised curriculum, student engagement, student motivation

\author{
Editorial on the Research Topic
}

The Impact of Place-Based Contextualised Curriculum on Student Engagement and Motivation in STEM Education

There is an imperative to educate our future citizens and STEM professionals, but at the same time in many countries, there are declining rates of STEM participation and achievement amongst our children in K-12 educational settings (Kennedy et al., 2014; Prendergast et al., 2014). How can we improve student engagement and motivation in STEM subjects? How can place-based contextualised approaches to teaching and learning improve teaching and learning in our schools?

Many students see STEM subjects as abstract and disconnected from their lives, leading to

Edited and reviewed by: Lianghuo Fan, East China Normal University, China

*Correspondence: Kathryn Holmes K.holmes@westernsydney.edu.au

Specialty section: This article was submitted to STEM Education, a section of the journal Frontiers in Education

Received: 01 December 2021 Accepted: 13 December 2021 Published: 07 January 2022

Citation:

Holmes K, Berger N, Mackenzie E, Attard C, Johnson P, Fitzmaurice O, O'Meara N and Ryan V (2022) Editorial:

The Impact of Place-Based Contextualised Curriculum on Student Engagement and Motivation in

STEM Education.

Front. Educ. 6:826656.

doi: 10.3389/feduc.2021.826656 disengagement and reduced levels of participation in STEM subjects in the senior years of formal schooling. Disengagement in STEM is related to factors such as self-efficacy, prior achievement, perceived levels of difficulty, interest, gender stereotypes and career aspirations (Britner and Pajares, 2006; Watt et al., 2012; Wang and Degol, 2013). Females often perceive STEM disciplines to be "male-oriented" and not focussed on societal benefits, leading them to disengage, particularly in subjects like engineering and computer science (Archer et al., 2013). Finding ways to challenge STEM stereotypes and to mediate the perceived difficulty of STEM subjects may help to address some of these barriers. Also, developing ways to improve interest in STEM subjects, so that students see the relevance and value of STEM in their lives, may improve STEM participation rates (Berger et al., 2020).

We launched this Research Topic to elicit new knowledge about teaching STEM subjects through contextualised curricula approaches that engage students by making the learning relevant to them. The six articles in this Research Topic draw on studies examining teacher capacity to develop and deliver integrated STEM curricula, reasons for student disengagement with STEM and the benefits and limitations of authentic STEM learning programs.

Delahunty et al. examined Irish primary teachers' perspectives on integrated STEM curriculum models, questioning the assumption that they can be readily implemented in primary school settings. They found that teachers were generally in favour of integrated approaches, noting benefits to students such as improved student learning in each of the STEM disciplines, alongside the development of collaborative skills and opportunities for authentic problem-solving. However, they also found that teachers were not always confident to integrate disciplines as they had little experience in teaching across multiple disciplines and in some cases a perceived lack of discipline knowledge. The teachers also emphasised the overcrowded nature of the primary curriculum, perceiving integrated STEM as additional to the existing curriculum rather than a variation in the mode of delivery. Resourcing was also identified as 
a significant barrier, due to the hands-on nature of this type of learning in the primary school setting. To address these issues the primary teachers in this study called for a nationally developed integrated STEM curriculum and a need for effective and available professional development in integrated STEM was also identified if integrated STEM was to become mainstream.

Fraser et al. addressed the issue of lower STEM participation levels amongst rural, regional and remote (RRR) communities. They made the case for improving student engagement via greater visibility of "place-based" knowledges, including Aboriginal STEM knowledges. They drew on the theoretical perspectives of Foucault and Bourdieu to propose a new analytical tool: the Placebased STEM-alignment framework. This tool provides a framework to observe, map and document place-based STEM discourses across both academic and community stakeholders. By doing so it is envisaged that RRR students can engage with and learn STEM with a better-aligned sense of identity, creating stronger pathways towards further STEM education, training and careers.

Attard et al. reported on a teacher professional learning program designed to support teachers to teach STEM through inquiry-based approaches drawing on expertise and knowledge from industry partners. By involving experts from two large infrastructure projects, student engagement was enhanced across operative, cognitive and affective domains. Both students and teachers appreciated the contextualisation of learning within the infrastructure projects that were impacting on their local environments. Also, the opportunity for students to apply knowledge to authentic place-based contexts was beneficial along with the community connections made throughout the inquiry based learning approaches.

Similarly, Gallay et al. reported on a program allowing students to engage with local environmental issues as a vehicle for a contextualised curriculum in mathematics and science. The study was conducted in ethnically and socioeconomically nondominant urban communities and found that the students did engage with STEM when opportunities were provided for students to solve local problems. The projects were linked with the promotion of civic action, leading youth to feel connected and empowered to have a positive impact on their communities in addition to gaining valuable and authentic STEM knowledge.

Holmes et al. examined the research literature from 2016-2021 to determine the benefits and limitations of localised STEM curriculum including studies based in kindergartens through to Year 12. Twenty-five studies were identified and synthesised identifying a range of benefits for students, including increased student aspirations, enjoyment, interest and engagement in STEM. The

\section{REFERENCES}

Archer, L., DeWitt, J., Osborne, J., Dillon, J., Willis, B., and Wong, B. (2013). 'Not Girly, Not Sexy, Not Glamorous': Primary School Girls' and Parents' Constructions of Science Aspirations1. Pedagogy, Cult. Soc. 21 (1), 171-194. doi:10.1080/14681366.2012.748676

Berger, N., Mackenzie, E., and Holmes, K. (2020). Positive Attitudes Towards Mathematics and Science Are Mutually Beneficial for Student Achievement: A Latent Profile Analysis of TIMSS 2015. Aust. Educ. Res. 47 (3), 409-444. doi:10.1007/s13384-020-00379-8 review also identified increases in transferable skills amongst students, such as teamwork, communication skills, increased pride in local communities and opportunities for empowerment and community advocacy. The review also revealed limitations of localised and contextualised STEM learning. These included the restriction of time as a barrier for teachers to overcome in planning and delivering these types of learning opportunities. Also, there was evidence that community engagement in localised learning was often difficult to secure, stymying the development of authentic, connected STEM learning possibilities.

Videla et al. proposed an enactive and ecological approach to STEM and STEAM learning, promoting interactions between learners and digital and/or analogue learning affordances within a systems theory perspective. This approach was then exemplified through two empirical studies conducted in New Zealand and Chile. The authors report on the benefits of the dynamics of the interplay between sensorimotor contingencies and attentional anchors. Basing learning on authentic STEM problems can assist learners to develop naive motor skills into scientific skills with contextual utility. This holistic approach is designed to have practical and empirical implications for STEM pedagogies and curriculum design.

Collectively these articles identify the value of contextualised approaches to STEM teaching and learning for both students and teachers. STEM fields are evolving rapidly and schools need to have ongoing and secure connections with STEM industries and community partners in order to keep up to date with new developments so that learning remains relevant and authentic. This type of learning creates new demands on teachers in terms of maintaining relationships with STEM stakeholders outside of the school community and in relation to the time required to plan integrated curriculum programs (Margot and Kettler, 2019). However, the benefits are clear. There is great potential for improved student engagement and interest in STEM and longerterm benefits such as increased STEM career aspirations (Shahali et al., 2017; Martín-Páez et al., 2019). These benefits are particularly salient for RRR students and those from disadvantaged backgrounds. The solutions reported in these papers provide some direction for those interested in improving STEM education and for researchers interested in progressing STEM education research.

\section{AUTHOR CONTRIBUTIONS}

$\mathrm{KH}$ led the writing of the editorial with all authors contributing to the final paper.

Britner, S. L., and Pajares, F. (2006). Sources of Science Self-Efficacy Beliefs of Middle School Students. J. Res. Sci. Teach. 43 (5), 485-499. doi:10.1002/tea.20131

Kennedy, J., Lyons, T., and Quinn, F. (2014). The Continuing Decline of Science and Mathematics Enrolments in Australian High Schools. Teach. Sci. 60 (2), 34-46. doi:10.3316/aeipt.203841

Margot, K. C., and Kettler, T. (2019). Teachers' Perception of STEM Integration and Education: a Systematic Literature Review. IJ STEM Ed. 6 (2), 1. doi:10.1186/s40594-018-0151-2

Martín-Páez, T., Aguilera, D., Perales-Palacios, F. J., and Vílchez-González, J. M. (2019). What Are We Talking about when We Talk about STEM Education? A Review of Literature. Sci. Ed. 103 (4), 799-822. doi:10.1002/sce.21522 
Mohd Shahali, E. H., Halim, L., Rasul, M. S., Osman, K., and Zulkifeli, M. A. (2016). STEM Learning through Engineering Design: Impact on Middle Secondary Students' Interest towards STEM. Eurasia J. Math. Sci. T. 13 (5), 1189-1211. doi:10.12973/eurasia.2017.00667a

Prendergast, M., Johnson, P., Fitzmaurice, O., Liston, M., O'Keeffe, L., and O'Meara, N. (2014). Mathematical Thinking: Challenging Prospective Teachers to Do More Than 'talk the Talk'. Int. J. Math. Education Sci. Technology. 45 (5), 635-647. doi:10.1080/0020739X.2013.868538

Wang, M. T., and Degol, J. (2013). Motivational Pathways to STEM Career Choices: Using Expectancy-Value Perspective to Understand Individual and Gender Differences in STEM Fields. Dev. Rev. 33 (4), 304-340. doi:10.1016/ j.dr.2013.08.001

Watt, H. M., Shapka, J. D., Morris, Z. A., Durik, A. M., Keating, D. P., and Eccles, J. S. (2012). Gendered Motivational Processes Affecting High School Mathematics Participation, Educational Aspirations, and Career Plans: A Comparison of Samples From Australia, Canada, and the United States. Dev. Psychol. 48 (6), 1594-1611. doi:10.1037/a0027838
Conflict of Interest: The authors declare that the research was conducted in the absence of any commercial or financial relationships that could be construed as a potential conflict of interest.

Publisher's Note: All claims expressed in this article are solely those of the authors and do not necessarily represent those of their affiliated organizations, or those of the publisher, the editors and the reviewers. Any product that may be evaluated in this article, or claim that may be made by its manufacturer, is not guaranteed or endorsed by the publisher.

Copyright (c) 2022 Holmes, Berger, Mackenzie, Attard, Johnson, Fitzmaurice, O'Meara and Ryan. This is an open-access article distributed under the terms of the Creative Commons Attribution License (CC BY). The use, distribution or reproduction in other forums is permitted, provided the original author(s) and the copyright owner(s) are credited and that the original publication in this journal is cited, in accordance with accepted academic practice. No use, distribution or reproduction is permitted which does not comply with these terms. 